\title{
Influence of Fasting on Attention and Concentration of Diabetic Fasting Patients during the Month of Ramadan
}

Loubna Oukit", Sana Rafi, Ghizlane El Mghari, Nawal El Ansari

Department of Endocrinology, Mohammed VI university hospital, Marrakesh, Morocco

DOI: $10.36347 /$ simcr.2020.v08i01.021

| Received: 15.01.2020 | Accepted: 22.01.2020 | Published: 24.01.2020

*Corresponding author: Loubna Oukit

Abstract

Case Report

Introduction: The impact of fasting on cognitive performance in type 2 diabetics has long been a subject of controversy. We will focus in this work on its influence on neurocognitive performance in this population using two tests. Patients and method: Type 2 diabetic patients who voluntarily agreed to participate in the study, during the month of Ramadan 1437 (July 2017). Two tests were used: Cancellation Task and Digit Spam. The parameters were evaluated and compared before, during and after the month of Ramadan. Results: The study involved 38 type 2 diabetic patients, $62 \%$ were female, with an average age of 52.9 years. The average duration of diabetes progression was 4.62 years. The average glycated hemoglobin before Ramadan was $7.2 \%$. All the patients maintained the fast throughout the month of Ramadan. Digit Span test average was 5.01 before Ramadan, 5.76 during Ramadan and 4.97 after Ramadan. Regarding Cancellation Task test, the comparison highlighted a significant difference in response time and test scores between the measurements during Ramadan and that after Ramadan. Discussion: The data comfort that fasting would affect spatial recognition functions in type 2 diabetics. However, the assessment of short-term memory found no differences between the three periods. Regular food intake, in particular, carbohydrate intake, which is essential for proper neuronal functioning, would be involved in these data changes. These two tests are to be adapted on a larger scale, constituting a real alternative for exploring neurocognitive capacities, in particular in diabetics.

Keywords: Fasting, Ramadan, Attention, Cognition.

Copyright @ 2020: This is an open-access article distributed under the terms of the Creative Commons Attribution license which permits unrestricted use, distribution, and reproduction in any medium for non-commercial use (NonCommercial, or CC-BY-NC) provided the original author and source are credited.

\section{INTRODUCTION}

Ramadan is a sacred month during which fast is practiced, which means that from sunrise to sunset food and drink are interrupted. This duration of sunshine is variable depending on the time of the year between ten to sixteen hours. Of course, religion exempts anyone sick or unable to continue this practice. Only, in addition to the religious aspect, the sociocultural context is very important, making this month a social and family meeting of sharing that the patients do not want to miss. In fact, very often exempt patients such as diabetic ones insist on fasting. In addition, cognitive functions, attention, concentration, are influenced by many internal and external stimuli. The influence of the parameters of the environment is widely established, the permanent stimulation of these functions allows their development.

The objective of our study was to assess the influence and impact of fasting on cognitive functions, especially attention and concentration, in fasting diabetic patients.

\section{Patients and Method}

The study was prospective, concerning type 2 diabetic patients on oral antidiabetic medication, well balanced or in the expected objectives, without contraindication to the fast. Patient recruitment was done by phone, from a database of contacts of the patients followed. They were assessed three times, before the month of Ramadan, during and after this month of fasting.

The assessment included two aspects: epidemiological and anthropometric data, as well as glycated hemoglobin. Also, patients were asked to do two tests:

1 - The Cancellation Tasks (Mesulam and Weintraub) which is a method of assessing attention and visuospatial functions. 


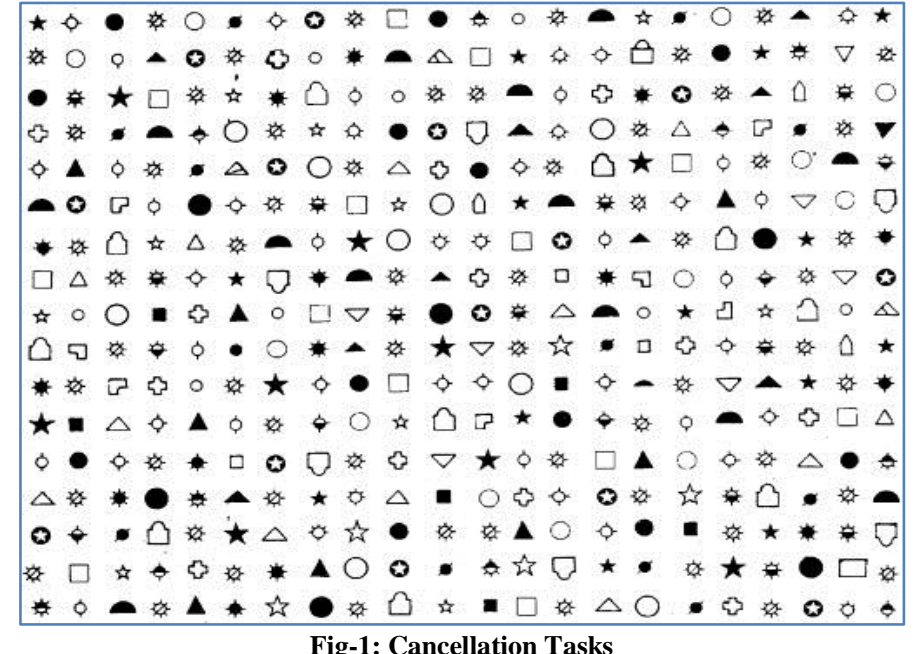

The principle is as follows: Each sheet contains 60 targets, 15 per quadrant (Fig 1). One of the targets is chosen, the subject is brought to mark all these targets as quickly as possible, and after 300 seconds the test is interrupted. The number of correct answers is counted as well as the time spent on the test.
The cards were to be completed by the patient himself. The score was calculated according to the formula: (correct answers / total number of targets) $\mathrm{x}$ (correct answers / duration of the test).

2 - The Digit Span Test (DST) which allows the evaluation of short-term memory (Fig 2).

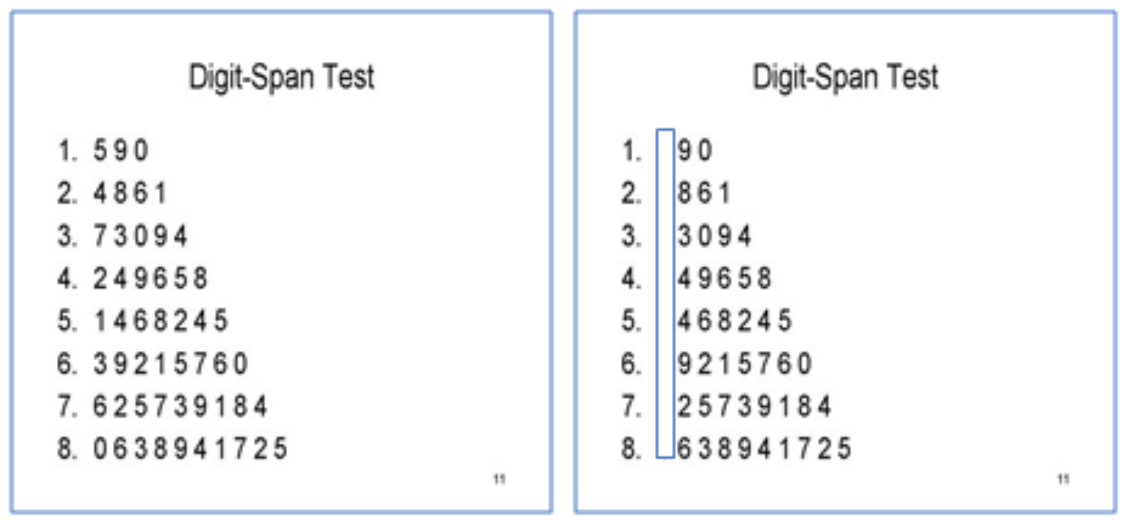

Fig-2: Digit Spam Test

Rules are as follow: numbers are announced aloud at the rate of one per second and at the end of each sequence the participant must repeat it in the same order. If he makes a mistake twice in the same sequence, it is stopped and a new sequence is started, this time the numbers must be repeated backwards. The score corresponds to how many series are repeated correctly, the final score is calculated by adding the two scores of the series repeated backwards and the one forwards.

\section{RESULTS \\ Demographic data}

The sample included 38 subjects, ranging in age from 38 to 75 , and the average was 52.9 years. Our sample included $38 \%$ men and $52 \%$ women. All socioeconomic profiles were represented, $29 \%$ illiterate, $8 \%$ having attained higher education. The average glycemic balance was $7.2 \%$ of $\mathrm{HbA1c}$. The treatment consisted of $39 \%$ metformin, $25 \%$ sulfonamides, $22 \%$ insulin, $14 \%$ combinations.

\section{Responses to the tests: (Table I)}

Table-1: Results to the different tests

\begin{tabular}{|l|l|l|l|l|}
\hline & $\begin{array}{l}\text { Before } \\
\text { Ramadan }\end{array}$ & $\begin{array}{l}\text { During } \\
\text { Ramadan }\end{array}$ & $\begin{array}{l}\text { After } \\
\text { Ramadan }\end{array}$ & Observations \\
\hline Digit Spam Test & 5.01 & 5.76 & 4.97 & No significant difference between the three results \\
\hline Cancellation Task: Score & 44.33 & 49.53 & 50.86 & No significant difference \\
\hline $\begin{array}{l}\text { Cancellation Task: time } \\
\text { of response }\end{array}$ & 261.08 & 256.5 & 255.26 & Significant difference for the time of response \\
\hline
\end{tabular}




\section{DiscuSSION}

The evaluation of diabetic patient during the month of Ramadan has often been a subject studied on different points [1,2]: eating habits, physical activity, blood pressure and glycemic balance, body composition, metabolic and clinical evaluation. In addition, few studies have looked at other aspects of fasting influence, notably intellectual or cognitive aspects.

On other hand, many tests have been developed in order to assess cognitive functions, while remaining adapted to different intellectual levels, especially shaped for the lowest ones. We used two of them: Digit Span Test and the Cancellation Task Test.

Cancellation Task Test has long been used in the evaluation of visiospatial functions and attention, psychomotor speed and visual screening [3], especially in subjects with low intellectual level allowing, as in our case, not to bias the results by this single parameter, as evaluated in a Brazilian study [3]. An adult free of any disease, aged under 65 , do the test in less than two minutes, in older subjects it can take three minutes $[4,5]$.

Thus, Digit Span Test is one of the oldest and best-established methods for the neuropsychological assessment of short-term verbal memory $[6,7]$. It is a subcategory of the Wechsler Intelligence Scale, which measures the ability to repeat a series numbers using memory [8]. In particular, it has been used in the evaluation of the memory in patients who had a stroke [6] and in subjects after anesthesia [8]. In certain studies, the influence of fasting on intellectual functions has been evaluated in particular using these tools.

A reduction in attention is found in preadolescents who fast in a study by Farook et al. it used the Cambridge Neuropsychological Test Automated Battery, which is a validated and approved test for assessing cognitive function in children [9]. Also, during the fast, attention is impaired according to the evaluation of the study by Dolu et al. [10], while no significant influence was found in an Iranian study of young women [11].

However, this influence was not noted in all aspects of our assessment. It concerned patient's response time, but not spatial recognition or short-term memory.

There is evidence that the fast during the month of Ramadan has a negative impact on people's attention and reaction time. However, in the study by Afzal-Amin et al. which explored the association between the fast, cognitive performance and mood, the subjects had less energy while fasting, but there was no direct effect on their concentration, mood or intellectual performance. On the other hand, the impact was real on the Cancellation Task on visual attention [12].

It was important in our study to eliminate some biases such as illiteracy or the level of understanding of the exercise but also the motivation to reliably complete the tests.

In our case study, according to the data identified, fasting would have a real impact on spatial recognition functions in type 2 diabetes, and an improved response time when non fasting. However, the assessment of short-term memory found no difference between the three periods.

Thus, caloric intake, essentially carbohydrate, essential for proper neuronal functioning would be involved in reducing the response time between periods of fast. This is why regular food intake plays a vital role in maintaining neurocognitive functions at an appropriate level of functioning. Also, the two tests used found converging results despite the complexity of neurocognitive processes and concentration functions. These two tests are to be adapted on a larger scale, constituting a real option for the exploration of neurocognitive capacities, in particular, in diabetic patients.

\section{CONCLUSION}

The fast during the month of Ramadan combines some major upheavals, marked in particular by the suspension of carbohydrate and water intake during the day [13]. They assume changes in lifestyle and a repercussion, in particular on neurocognitive performance. After testing cognitive and neuropsychic aspects related to the fast and comparing them with the data in the literature, it seems clear that the influence is less important than expected and it only concerns a few particular aspects, thus supposing an adaptation of the organism to the fast. However, the use of these tests should be extended to a larger scale.

\section{REFERENCE}

1. Hassanein M, Al-Arouj M, Hamdy O. Diabetes and Ramadan: Practical guidelines. Diabetes Research and Clinical Practice. 2017;126:303-316

2. Salti I, Benard E, Detournay B. A population-based study of diabetes and its characteristics during the fasting month of Ramadan in 13 countries: results of the epidemiology of diabetes and Ramadan 1422/2001 (EPIDIAR) study. Diabetes Care. 2004;27:2306-11

3. SM. Dozzi Brucki, R. Nitrini. Cancellation task in very low educated people Archives of Clinical Neuropsychology. 2008; 23: 139-147

4. Mesulam MM. Principles of behavioral neurology. Philadelphia: FA Davis Company. 1985 
5. Mesulam MM. Principles of behavioral neurology (2nd Ed.). New York: Oxford University Press. 2000

6. David L. Woods, Kishiyama MM, Yund EW, Herron TJ, Edwards B, Poliva O, Hink RF, Bruce Reed. Improving digit span assessment of shortterm verbal memory. J Clin Exp Neuropsychol. 2011 ; 33(1): 101-111

7. Richardson JT. Measures of short-term memory: A historical review. 2007;43(5):635-650

8. Chang-Jae Kim, Sang-hyun Hong, Byung-Sam Kim. Comparison of various tests designed to assess the recovery of cognitive and psychomotor function after ambulatory anesthesia. Korean J Anesthesiol. 2008; 55 (3):291-297

9. Abdulaziz Farooq, Christopher Paul Herrera, Fuad Almudahka, Rita Mansour. A Prospective Study of the Physiological and Neurobehavioral Effects of Ramadan Fasting in Preteen and Teenage Boys. J Acad Nutr Diet. 2015;115:889-897
10. Nazan Dolu, Ahmet Yüksek, Alparslan Sizer, Mehmet Alay. Arousal and continuous attention during Ramadan intermittent fasting. Journal of Basic \& Clinical Physiology and Pharmacology. 2007; 18(4): 315-322.

11. Najafabadi MG, Nikoukar LR, Memari A, Ekhtiari H, Beygil S. Does Ramadan Fasting Adversely Affect Cognitive Function in Young Females? Hindawi Publishing Corporation Scientifica. 2015; 6.

12. Afzal-Amin SN, Gardner M, Edmonds CJ. Does fasting during Ramadan affect children's cognition and mood? A pilot study of children's performance and teachers' perceptions. 2014; 342-362

13. Alkandari JR, Maughan RJ, Roky R, Aziz AR, Karli U. The implications of Ramadan fasting for human health and well-being. J Sports Sci. 2012;30(1):S9-S19. 